\title{
A developmental angle to understanding the mechanisms of biased cognitions in social anxiety
}

\author{
Simone P. W. Haller ${ }^{1 *}$, Kathrin Cohen Kadosh ${ }^{1}$ and Jennifer Y. F. Lau ${ }^{1,2}$ \\ ' Department of Experimental Psychology, University of Oxford, Oxford, UK \\ ${ }^{2}$ Department of Psychology, Institute of Psychiatry, King's College London, London, UK \\ *Correspondence: simone.haller@psy.ox.ac.auk
}

Edited by:

Wolf-Gero Lange, Radboud University Nijmegen, Netherlands

Reviewed by:

Esther Allart, ProPersona, Netherlands

Keywords: social anxiety, cognitive bias, attention, interpretation, neurocognitive development, fMRI, children and adolescents

\section{INTRODUCTION}

Social anxiety disorder (SAD) is debilitating and common, affecting 7.3-12.1\% of the population (e.g., Wittchen et al., 1999; Kessler et al., 2005). Age-of-onset data show that SAD symptoms are often first experienced in late childhood or adolescence (Kessler et al., 2005). While adolescence is a period when many typical social fears and worries emerge, major questions remain as to why some youths are more vulnerable to experiencing persistent and impairing social anxiety. A key gap in current theoretical models of SAD etiology is an understanding of the mechanisms by which risk factors are expressed during development. In this opinion paper, we address this gap by first discussing the nature of age-typical increases in social fears and worries in the transition to adolescence and outlining possible brain-based developmental mechanisms by which these arise. Next, we discuss how these age-typical changes in neurocognitive functioning might, in a subset of adolescents, enable maladaptive processing biases in relation to social cues to emerge or be exacerbated. These processing biases may, in turn, contribute to the onset of persistent social anxiety.

\section{ADOLESCENCE: A PERIOD OF AGE-TYPICAL INCREASES IN SOCIAL FEARS AND WORRIES}

Adolescence is a transitional period demarcated by the onset of puberty, and ending with the assumption of a stable adult role (Lerner and Steinberg, 2004). This transitional period involves substantial physiological and psychological changes, currently understood to be orchestrated by a combination of experience-dependent and biologically programmed regulation of gene expression (Nelson et al., 2005; Gajados et al., 2010). Central to adolescent developments are hormonal changes associated with puberty. These likely initiate a cascade of morphological and neural maturations, which significantly impact on cognition and information processing (Sisk and Foster, 2004; Blakemore et al., 2010; Goddings et al., 2013). Of particular interest in the context of this opinion paper are the effects of these maturational changes on the processing of affective and social stimuli. In the last decade, there has been a surge in investigations of typical changes in the functioning of limbic and prefrontal networks across development, especially during social-affective processing (e.g., Pfeifer and Blakemore, 2012). Cross-sectional comparisons of functional neuroimaging data from multiple child/adolescent/adult age groups may lend insight into how typical developmental changes in the brain can give rise to adolescent-typical behaviors of heightened "emotionality" and "sociality". In turn, these may explain age-associated changes in social fears and worries in adolescence.

What typical neurodevelopmental changes might increase "emotionality" (that is, increased avoidance of threats and approach of rewards) across age? There is now a convincing corpus of data available documenting changes in the sensitivity of subcortical regions involved in basic processing of threat and reward such as the amygdalae and striatum. These data broadly suggest a peak in the neural response to monetary rewards, emotional faces and peer feedback in early to mid-adolescence, before decreasing toward adulthood (e.g., Monk et al., 2003; Ernst et al., 2005; Galvan et al., 2006; Hare et al., 2008; Van Leijenhorst et al., 2010; Pfeifer et al., 2011; Somerville et al., 2011; Chein et al., 2012; Gee et al., 2013). More protracted changes have also been noted in regulatory regions involved in modulating arousal. The few cross-sectional functional magnetic resonance imaging (fMRI) studies of adolescents have consistently found differences in medial and lateral functional subdivisions of the prefrontal cortex (PFC) in response to emotionally provocative stimuli between adolescents and adults (e.g., Yurgelun-Todd and Killgore, 2006; Masten et al., 2009; Gunther Moor et al., 2010, 2012; Lau et al., 2011; Pitskel et al., 2011; McRae et al., 2012). However, the directionality of these developmental differences is not always consistent, possibly because of variations associated with the social-motivational context of the task (see Crone and Dahl, 2012 for in-depth discussion). Nonetheless, additional recruitment of medial and lateral PFC regions in older age groups (relative to younger participants) has been tentatively interpreted as reflecting an increased ability to recruit these regions to effectively down-regulate subcortical arousal with age (e.g., Gunther Moor et al., 2010; Casey et al., 2011). Further support for this interpretation comes from studies showing that regulatory functional connectivity between PFC and subcortical regions continues to mature throughout adolescence (Hare et al., 2008; Pitskel et al., 2011; Gee et al., 2013). Synthesis of these data suggests that protracted maturation of prefrontal engagement together with a heightened reactivity of limbic regions to threatening 
and rewarding stimuli may be responsible for increased emotional responses in adolescence. Notably, these studies of ageassociated functional differences occur against a backdrop of structural developments in these regions too, with data pointing to localized linear and non-linear restructuring as well as further integration within networks (e.g., Giedd et al., 1999; Paus et al., 1999; Sowell et al., 1999; Gogtay et al., 2004; Dennis et al., 2013).

What typical neurodevelopmental changes might increase "sociality" (that is, increased motivational salience of peers and understanding of complex social situations) across age? Continuous development throughout adolescence has been documented in the network involved in the understanding of others' behavior in terms of motivations, thoughts and feeling states ("mentalizing") (Blakemore, 2008; Mills et al., 2014). Developmental studies of mentalizing have consistently found a (relative) decrease in anterior/dorsal medial PFC activity and increase in posterior-temporal areas (such as the temporo-parietal junction and superior temporal sulcus) in response to tasks requiring mental state attribution when comparing early/mid adolescent to adult groups (Wang et al., 2006; Blakemore et al., 2007; Burnett et al., 2009; Guroglu et al., 2011). More recent studies have employed multiple adolescent age groups and have confirmed a continuous shift in functional contributions from frontal to temporal areas across adolescence whilst engaged in thinking about mental states (Gunther Moor et al., 2011; Van den Bos et al., 2011)_findings that have been suggested to reflect increased automaticity of engaging in mentalizing across adolescence (e.g., Blakemore, 2008; Van den Bos et al., 2011). Presumably such neurocognitive changes prepare the adolescent for navigation in a novel and possibly more complex social world.

In summary, changes in brain networks engaged by social-affective stimuli across adolescence may result in greater affective responding and a greater engagement with, and understanding of, complex interpersonal situations. These age-typical changes may, on the one hand, allow for more flexible responses enabling the adolescent to adapt rapidly to changing social contextual demands (Crone and
Dahl, 2012). Yet, on the other hand, these normative brain developments, which change the perception of and importance placed on the social world, may increase social fears and worries. This may be particularly crucial given that some social environments are changing. For example, school transitions often mean longer time in school and greater workload, as well as more time spent interacting with peers socially and academically. Such changes may increase the opportunities for new academic pressures to emerge, and new peer groups and hierarchies to be formed.

\section{ADOLESCENCE: A PERIOD OF PRECIPITATING INDIVIDUAL DIFFERENCES IN SOCIAL ANXIETY}

While we suggest that most adolescents will experience age-associated increases in social fears and worries, in a minority of adolescents, more distressing forms of social anxiety may also emerge and persist. A key question is what makes these individuals different? Similar to adult models of SAD, theoretical considerations of child and adolescent SAD have emphasized biases in information processing (Clark and Wells, 1995; Rapee and Heimberg, 1997; Ollendick and Hirshfeld-Becker, 2002; Jarcho et al., 2013). Attention biases, that is, systematic differences in orienting to threat cues, have been documented in socially anxious children and adolescents (Stirling et al., 2006; Roy et al., 2008) and even in at-risk infants (offspring of socially anxious mothers) as young as 10 weeks (Creswell et al., 2008). Biases in the interpretation of ambiguous social information have also been found in socially anxious youths (Haller et al. A novel picture-based tool for measuring interpretation biases in adolescents, manuscript in preparation; Miers et al., 2008) although, interestingly, linkages between biased interpretations and symptoms are less consistently found in younger children (Waters et al., 2008; In-Albon et al., 2009; Creswell et al., 2013). It may either be that current measurement tools are not suitable for detecting interpretation biases in younger populations or that interpretation biases do not mature as risk factors until later in adolescence. Finally, biases in expectations of the outcomes of socialevaluative situations also characterize socially anxious individuals and at-risk populations (Cartwright-Hatton et al., 2003, 2005; Pass et al., 2012).

Recent fMRI studies have suggested that in adults, SAD-linked cognitive biases may be associated with individual differences in brain activity. Thus, biases in attention and the tendency to perceive ambiguous social cues such as neutral facial expressions as negative have been linked to impaired regulatory recruitment of fronto-amygdalae circuits and increased emotion-related neural responses of limbic areas in SAD individuals (e.g., Cooney et al., 2006; Blair et al., 2008). The few studies investigating the neural substrates of information processing and cognitions in adolescents with social concerns mostly find similar results (Killgore and JurgelunTodd, 2005; Pérez-Edgar et al., 2007; Guyer et al., 2008, 2014).

How might age-normative neural changes in social-affective regions impact on the expression of individual differences in cognitive biases thereby increasing vulnerability to SAD in adolescence? We suggest that age-typical changes in emotionality and sociality in adolescence may magnify differences across individuals such that those who already fall at the end of the continuous distribution shift further toward the extreme end. Speculatively, this can occur through two routes. First, developmental changes in the sensitivity of the "emotional brain" may further amplify attention and expectancy biases for potential threat cues. Bi-directional interactions between pre-existing cognitive biases and the plasticity of the adolescent brain may serve to amplify negative effects over time. Pre-existing cognitive biases will affect functional restructuring by biasing incoming information to further sensitize socio-affective networks. Hence, individuals with a pre-existing tendency to attend to negative aspects of social cues or situations-or to expect negative outcomes from these-may experience these to a greater degree and, to alleviate distress, may engage in maladaptive behavioral strategies such as avoidance. This will set up a vicious cycle, which, over time, reinforces these pre-existing maladaptive biases.

Secondly, developmental changes in the "social brain" may act as a vehicle for the expression of biases at the level of interpretation. As increased mentalizing 
abilities (being able to generate more "mental explanations" for others' behavior) emerge. The emergence of increased mentalizing abilities across adolescence may result in an increase in perceived complexity and ambiguity of daily social situations. Specifically, as these maturational brain developments are paralleled by increases in time spent with peers, this change in perception of social interactions may "bring out" in some individuals the tendency to interpret socially ambiguous cues in a more negative manner. This could also explain findings of why interpretation biases are not consistently found in younger populations-it may be that such biases in interpretation only become evident once these socio-cognitive capacities are attained.

In order to empirically investigate these hypotheses, studies need to assess whether certain neurocognitive factors characterize individuals with social anxiety at particular ages or at particular pubertal developmental stages. This can be done by looking at SAD-linked processing biases in individuals with high and low social anxiety (or with and without SAD) across different developmental age groups. Our prediction is that while attention, expectancy and interpretation biases at the behavioral and neural level characterize all participants with high levels of social anxiety (or who meet criteria for SAD), these group differences will prove to be far stronger in adolescents than in children. Moreover, we would predict that these age-by-group interactions are mediated by changes in "emotionality" and "sociality". Such hypotheses await future empirical investigations.

\section{CONCLUSION}

This opinion paper has highlighted how neuro-scientific insights on the level of normative functional changes during adolescence can generate novel hypotheses about the mechanisms underlying the emergence or exacerbation of individual differences related to social anxiety. We have described ways in which normative neurodevelopmental progressions could magnify pre-existing cognitive biases in attention, interpretation and expectations that are characteristic of persistent and impairing social fears and worries. We further provided directions as to how these hypotheses should be empirically investigated. Adolescence as a time of increased plasticity may also be an optimal time for administering neurocognitive interventions (e.g., Cohen Kadosh et al., 2013; Lau, 2013) as the exposure to specific adaptive or corrective experiences may result in long-term effects on neural architecture. Understanding the mechanisms by which normative neurodevelopmental changes may drive the expression of risk factors linked to social anxiety can extent current theoretical models of SAD and, in parallel, inform when early interventions should be effectively applied.

\section{REFERENCES}

Blair, K., Geraci, M., Devido, J., McCaffrey, D., Chen, G., Vythilingam, M., et al. (2008). Neutral response to self- and other referential praise and criticism in generalized social phobia. Arch. Gen. Psychiatry 65, 1176-1184. doi: 10.1001/archpsyc. 65.10.1176

Blakemore, S.-J. (2008). The social brain in adolescence. Nat. Rev. Neurosci. 9, 267-277. doi: $10.1038 / \mathrm{nrn} 2353$

Blakemore, S. J., Burnett, S., and Dahl, R. E. (2010). The role of puberty in the developing adolescent brain. Hum. Brain Mapp. 31, 926-933. doi: 10.1002/hbm.21052

Blakemore, S.-J., den Ouden, H., Choudhury, S., and Frith, C. (2007). Adolescent development of the neural circuitry for thinking about intentions. Soc. Cogn. Affect. Neurosci. 2, 130-139. doi: 10.1093/scan/nsm009

Burnett, S., Bird, G., Moll, J., Frith, C., and Blakemore, S.-J. (2009). Development during adolescence of the neural processing of social emotion. J. Cogn. Neurosci. 21, 1736-1750. doi: 10.1162/jocn.2009.21121

Cartwright-Hatton, S., Hodges, L., and Porter, J. (2003). Social anxiety in childhood: the relationship with self and observer rated social skills. J. Child Psychol. Psychiatry 44, 737-742. doi: 10.1111/1469-7610.00159

Cartwright-Hatton, S., Tschernitz, N., and Gomersall, H. (2005). Social anxiety in children: social skills deficit, or cognitive distortion? Behav. Res. Ther. 43, 131-141. doi: 10.1016/j.brat.2003. 12.003

Casey, B. J., Jones, R. M., and Somerville, L. H. (2011). Braking and accelerating of the adolescent brain. J. Res. Adolesc. 21, 21-33. doi: 10.1111/j.15327795.2010.00712.x

Chein, J., Albert, D., Brien, L. O., Uckert, K., and Steinberg, L. (2012). Peers increase adolescent risk taking by enhancing activity in the brain's reward ciruitry. Dev. Sci. 14, 1-16. doi: 10.1111/j.14677687.2010.01035

Clark, D. M., and Wells, A. (1995). "A cognitive model of social phobia," in Social Phobia-Diagnosis, Assessment, and Treatment, eds R. G. Heimberg, M. Liebowitz, D. Hope, and F. Scheier (New York, NY: Guilford), 69-93.
Cohen Kadosh, K., Linden, D. E. J., and Lau, J. Y. (2013). Plasticity during childhood and adolescence: innovative approaches to investigating neurocognitive development Dev. Sci. 16, 574-583. doi: 10.1111/desc. 12054

Cooney, R. E., Atlas, L. Y., Joormann, J., Eugene, F, and Gotlib, I. H. (2006). Amygdala activation in the processing of neutral faces in social anxiety disorder: is neutral really neutral? Psychiatry Res. 148, 55-59. doi: 10.1016/j.pscychresns.2006. 05.003

Creswell, C., Murray, L., and Cooper, P. (2013). Interpretation and expectation in childhood anxiety disorders: age effects and social specificity. J. Abnorm. Child Psychol. doi: 10.1007/s10802-0139795-z. [Epub ahead of print].

Creswell, C., Woolgar, M., Cooper, P., Giannakakis, A., Schofield, E., Young, A. W., et al. (2008). Processing of faces and emotional expressions in infants at risk of social phobia. Cogn. Emot. 22, 437-458. doi: 10.1080/02699930701872392

Crone, E. A., and Dahl, R. E. (2012). Understanding adolescence as a period of social- affective engagement of goal flexibility. Nat. Rev. Neurosci. 13, 636-650. doi: 10.1038/nrn3313

Dennis, E. L., Jahanshad, N., McMahon, K. L., de Zubicaray, G. I., Martin, N. G., Hickie, I. B., et al. (2013). Development of brain structural connectivity between ages 12 and 30: a 4-Tesla diffusion imaging study in 439 adolescents and adults. Neuroimage 64, 671-684. doi: 10.1016/j.neuroimage.2012.09.004

Ernst, M., Nelson, E. E., Jazbec, S., McClure, E. B., Monk, C. S., Leibenluft, E., et al. (2005). Amygdala and nucleus accumbens in responses to receipt and omission of gains in adults and adolescents. Neuroimage 25, 1279-1291. doi: 10.1016/j.neuroimage.2004.12.038

Gajados, Z. K., Henderson, K. D., Hirschhorn, J. N., and Palmert, M. R. (2010). Genetic determinants of pubertal timing in the general population. Mol. Cell Endocrinol. 324, 21-29. doi: 10.1016/j.mce.2010.01.038

Galvan, A., Hare, T. A., Parra, C. E., Penn, J., Voss, H., Glover, G., et al. (2006). Earlier development of the accumbens relative to orbitofrontal cortex might underlie risk-taking behavior in adolescents. J. Neurosci. 26, 6885-6892. doi: 10.1523/ JNEUROSCI.1062-06.2006

Gee, D. G., Humphreys, K. L., Flannery, J. F., Goff, B. F., Telzer, E. H., Shapiro, M., et al. (2013). A developmental shift from positive to negative connectivity in human amygdala-prefrontal circuitry. J. Neurosci. 33, 4584-4593. doi: 10.1523/ JNEUROSCI.3446-12.2013

Giedd, J. N., Blumenthal, J., Jeffries, N. O., Castellanos, F. X., Liu, H., Zijdenbos, A., et al. (1999). Brain development during childhood and adolescence: a longitudinal MRI study. Nat. Neurosci. 2, 861-863.

Goddings, A. L., Mills, K. L., Clasen, L. S., Giedd J. N., Viner, R. M., and Blakemore, S. J. (2013). The influence of puberty on subcortical brain development. Neuroimage. doi: 10.1016/j.neuroimage.2013.09.073. [Epub ahead of print].

Gogtay, N., Giedd, J. N., Lusk, L., Hayashi, K. M., Greenstein, D., Vaituzis, A. C., et al. (2004). 
Dynamic mapping of human cortical development during childhood through early adulthood. Proc. Natl. Acad. Sci. U.S.A. 101, 8174-8179. doi: 10.1073/pnas.0402680101

Gunther Moor, B., Güroglu, B., Op de Macks, Z. A., Rombouts, S. A. R. B., Van der Molen, M. W., and Crone, E. A. (2012). Social exclusion and punishment of excluders: neural correlates and developmental trajectories. Neuroimage 59, 708-717. doi: 10.1016/j.neuroimage.2011. 07.028

Gunther Moor, B., Macks, Z. A., Güroglu, B., Rombouts, S. A., Molen, M. W., and Crone, E. A. (2011). Neurodevelopmental changes of reading the mind in the eyes. Soc. Cogn. Affect. Neurosci. 7, 44-52. doi: 10.1093/scan/nsr020

Gunther Moor, B., van Leijenhorst, L., Rombouts, S. A., Crone, E. A., and van der Molen, M. W. (2010). Do you like me? Neural correlates of social evaluation and developmental trajectories. Soc. Neurosci. 5, 461-482. doi: 10.1080/174709109035 26155

Guroglu, B., van den Bos, W., van Dijk, E., Rombouts, S. A., and Crone, E. A. (2011). Dissociable brain networks involved in development of fairness considerations: understanding intentionality behind unfairness. Neuroimage 57, 634-641. doi: 10.1016/j.neuroimage.2011. 04.032

Guyer, A. E., Benson, B., Choate, V. R., Bar-Haim, Y., Perez-Edgar, K., Jarcho, J. M., et al. (2014). Lasting associations between early-childhood temperament and late-adolescent reward-circuitry response to peer feedback. Dev. Psychopathol. 26, 229-243. doi: 10.1017/S09545794130 00941

Guyer, A. E., Lau, J. Y. F., McClure-Tone, E. B., Parrish, J., Shiffrin, N. D., Reynolds, R. C., et al. (2008). Amygdala and ventrolateral prefrontal cortex function during anticipated peer evaluation in pediatric social anxiety. Arch. Gen. Psychiatry 65, 1303-1312. doi: 10.1001/archpsyc.65. 11.1303

Hare, T., Tottenham, N., Galvan, A., Voss, H. U., Glover, G. H., and Casey, B. J. (2008). Biological substrates of emotional reactivity and regulation in adolescence during an emotional gonogo task. Biol. Psychiatry 63, 927-934. doi: 10.1016/j.biopsych.2008.03.015

In-Albon, T., Dubi, K., Rapee, R. M., and Schneider, S. (2009). Forced choice reaction time paradigm in children with separation anxiety disorder, social phobia, and nonanxious controls. Behav. Res. Ther. 47, 1058-1065. doi: 10.1016/j.brat.2009. 08.003

Jarcho, J. M., Leibenluft, E., Walker, O. L., Fox, N. A., Pine, D. S., and Nelson, E. E. (2013). Neuroimaging studies of pediatric social anxiety: paradigms, pitfalls and a new direction for investigating the neural mechanisms. Biol. Mood Anxiety Disord. 3, 14. doi: 10.1186/2045-53 80-3-14

Kessler, R. C., Berglund, P., Demler, O., Jin, R., Merikangas, K. R., and Walters, E. E. (2005). Lifetime prevalence and age-of-onset distributions of DSM-IV in the national comorbidity survey replication. Arch. Gen. Psychiarty 62, 593-768. doi: 10.1001/archpsyc.62.6.593
Killgore, W. D. S., and Jurgelun-Todd, D. (2005). Social anxiety predicts amydala activation in adolescents viewing fearful faces. Neuroreport 16, 1671-1675. doi: 10.1097/01.wnr.0000180143. 99267.bd

Lau, J. Y. (2013). Cognitive bias modification of interpretations: a viable treatment for child and adolescent anxiety? Behav. Res. Ther. 51, 614-622. doi: 10.1016/j.brat.2013.07.001

Lau, J. Y., Britton, J. C., Nelson, E. E., Angold, A., Ernst, M., Goldwin, M., et al. (2011). Distinct neural signatures of threat learning in adolescents and adults. Proc. Natl Acad. Sci. U.S.A. 108, 4500-4505. doi: $10.1073 /$ pnas. 1005494108

Lerner, R. M., and Steinberg, L. (2004). Handbook of Adolescent Psychology. New Jersey: John Wiley and Sons. doi: 10.1002/9780471726746

Masten, C. L., Eisenberger, N. I., Borofsky, L. A., Pfeifer, J. H., McNealy, K., Mazziotta, J. C., et al. (2009). Neural correlates of social exclusion during adolescence: understanding the distress of peer rejection. Soc. Cogn. Affect. Neurosci. 4, 143-157. doi: 10.1093/scan/nsp007

McRae, K., Gross, J. J., Weber, J., Robertson, E. R., Sokol-Hessner, P., Ray, R. D., et al. (2012). The development of emotion regulation: an fMRI study of cognitive reappraisal in children, adolescents and young adults. Soc. Cogn. Affect. Neurosci. 7, 11-22. doi: 10.1093/scan/nsr093

Miers, A. C., Blöte, A. W., Bögels, S. M., and Westenberg, P. M. (2008). Interpretation bias and social anxiety in adolescents. J. Anxiety Disord. 22, 1462-1471. doi: 10.1016/j.janxdis.2008. 02.010

Mills, K. L., Lalonde, F., Clasen, L. S., Giedd, J. N., and Blakemore, S. J. (2014). Developmental changes in the structure of the social brain in late childhood and adolescence. Soc. Cogn. Affect. Neurosci. 9, 123-131. doi: 10.1093/scan/ nss 113

Monk, C. S., McClure, E. B., Nelson, E. E. Zarahn, E., Bilder, R. M., Leibenluft, E., et al. (2003). Adolescent immaturity in attentionrelated brain engagement to emotional facial expressions. Neuroimage, 20, 420-428. doi: 10.1016/S1053-8119(03)00355-0

Nelson, E. E., Leibenluft, E., McClure, E. B., and Pine, D. S. (2005). The social re-orientation of adolescence: a neuroscience perspective on the process and its relation to psychopathology. Psychol. Med. 35, 163-174. doi: 10.1017/S00332917040 03915

Ollendick, T. H., and Hirshfeld-Becker, D. R. (2002). The developmental psychopathology of social anxiety disorder. Biol. Psychiatry 51, 44-58. doi: 10.1016/S0006-3223(01) 01305-1

Pass, L., Arteche, A., Cooper, P., Creswell, C., and Murray, L. (2012). Doll Play narratives about starting school in children of socially anxious mothers, and their relation to subsequent child school-based anxiety. J. Abnorm. Child Psychol. 40, 1375-1384. doi: 10.1007/s10802-012-9645-4

Paus, T., Zijdenbos, A., Worsley, K., Collins, D. L., Blumenthal, J., Giedd, J. N., et al. (1999). Structural maturation of neural pathways in children and adolescents: in vivo study. Science 283, 1908-1911.
Pérez-Edgar, K., Roberson-Nay, R., Hardin, M. G., Poeth, K., Guyer, A. E., Nelson, E. E., et al. (2007). Attention alters neural responses to evocative faces in behaviorally inhibited adolescents. Neuroimage 35, 1538-1546. doi: 10.1016/j.neuroimage.2007.02.006

Pfeifer, J. H., and Blakemore, S. J. (2012). Adolescent social cognitive and affective neuroscience: past, present, and future. Soc. Cogn. Affect. Neurosci. 7, 1-10. doi: 10.1093/scan/nsr099

Pfeifer, J. H., Masten, C. L., Moore, W. E., Oswald, T. M., Mazziotta, J. C., Iacoboni, M., et al. (2011). Entering adolescence: resistance to peer influence, risky behavior, and neural changes in emotion reactivity. Neuron 69, 1029-1036. doi: 10.1016/j.neuron.2011.02.019

Pitskel, N. B., Bolling, D. Z., Kaiser, M. D., Crowley, M. J., and Pelphrey, K. A., (2011). How grossed out are you? The neural bases of emotion regulation from childhood to adolescence. Dev. Cogn. Neurosci. 1, 324-337. doi: 10.1016/j.den.2011. 03.004

Rapee, R. M., and Heimberg, R. G. (1997). A cognitive-behavioural model of anxiety in Social Phobia. Behav. Res. Ther. 35, 741-756.

Roy, K. A., Vasa, R. A., Bruck, M., Mogg, K., Bradley, B. P., Sweeney, M., et al. (2008). Attention bias toward threat in pediatric anxiety disorders. J. Am. Acad. Child Adolesc. Psychiatry 47, 1189-1196. doi: 10.1097/CHI.0b013e3181825ace

Sisk, C. L., and Foster, D. L. (2004). The neural basis of puberty and adolescence. Nat. Neurosci. 7, 1040-1047. doi: 10.1038/nn1326

Somerville, L. H., Hare, T., and Casey, B. J. (2011). Frontostriatal maturation predict cognitive control failure to appetitive cues in adolescents. J. Cogn. Neurosci. 23, 2123-2134. doi: 10.1162/jocn.2010.21572

Sowell, E. R., Thompson, P. M., Holmes, C. J., Jernigan, T. L. and Toga, A. W. (1999). In vivo evidence for post-adolescent brain maturation in frontal and striatal regions. Nat. Neurosci. 2, 859-861.

Stirling, L. J., Eley, T. C., and Clark, D. M. (2006). Preliminary evidence for an association between social anxiety symptoms and avoidance of negative faces in school-age children. J. Clin. Child Adolesc. Psychol. 35, 440-445. doi: 10.1207/s15374424jccp3503_9

Van den Bos, W., van Dijk, E., Westenberg, M., Rombouts, S. A., and Crone, E. A. (2011). Changing brains, changing perspectives: the neurocognitive development of reciprocity. Psychol. Sci. 22, 60-70. doi: 10.1177/09567976103 91102

Van Leijenhorst, L., Zanolie, K., Van Meel, C. S., Westenberg, P. M., Rombouts, S. A. R. B., and Crone, E. A. (2010). What motivates the adolescent? Brain regions mediating reward sensitivity across adolescence. Cereb. Cortex 20, 61-69. doi: 10.1093/cercor/bhp078

Wang, A. T., Lee, S. S., Sigman, M., and Dapretto, M. (2006). Developmental changes in the neural basis of interpreting communicative intent. Soc. Cogn. Affect. Neurosci. 1, 107-121. doi: 10.1093/scan/nsl018

Waters, A. M., Craske, M. G., Bergman, R. L., and Treanor, M. (2008). Threat interpretation 
bias as a vulnerability factor in childhood anxiety disorders. Behav. Res. Ther. 46, 39-47. doi: 10.1016/j.brat.2007.10.002

Wittchen, H. U., Stein, M. B., and Kessler, R. C. (1999). Social fears and social phobia in a community sample of adolescents and young adults: prevalence, risk factors and co-morbidity. Psychol. Med. 29, 309-323.

Yurgelun-Todd, D. A, and Killgore, W. D. S. (2006). Fear-related activity in the prefrontal cortex increases with age duringadolescence: a preliminary fMRI study. Neurosci. Lett. 406, 194-199. doi: 10.1016/j.neulet.2006.07.046

Received: 13 July 2013; accepted: 20 November 2013; published online: 25 February 2014.

Citation: Haller SPW, Cohen Kadosh K and Lau JYF (2014) A developmental angle to understanding the mechanisms of biased cognitions in social anxiety. Front. Hum. Neurosci. 7:846. doi: 10.3389/fnhum.2013.00846 This article was submitted to the journal Frontiers in Human Neuroscience.
Copyright (C) 2014 Haller, Cohen Kadosh and Lau. This is an open-access article distributed under the terms of the Creative Commons Attribution License (CCBY). The use, distribution or reproduction in other forums is permitted, provided the original author(s) or licensor are credited and that the original publication in this journal is cited, in accordance with accepted academic practice. No use, distribution or reproduction is permitted which does not comply with these terms. 